\title{
A STUDY ON WIND INDUCED VIBRATION ON LIGHTING POLES
}

\author{
Suma Devi ${ }^{1}$, L Govindaraju ${ }^{2}$ \\ ${ }^{1}$ Assistant Professor, Department Of Civil Engineering, Sri Venkateshwara College Of Engineering, Karnataka, India \\ ${ }^{2}$ Associate Professor, Department Of Civil Engineering, UVCE, Bangalore University, Karnataka, India
}

\begin{abstract}
This study was under taken to understand the failures of slender flexible street pole structures under dynamic excitation due to wind loads. It also focuses on the most plausible collapse cause for the failure of the poles. Highway lighting poles as slender flexible structures with low-level of inherent damping undergo wind-induced vibrations. Two different types of steel pole sections have been considered in this study, viz. one with a single horizontal arm and luminaire, called the single luminaire and the other with two horizontal arms and luminaires known as the double luminaire both with a tapering hollow circular section. The models have been analyzed using SAP2000 by adopting the finite element method. The poles have been analyzed for equivalent static force considering the gust effect factor and wind load has been calculated based on three codes of reference namely AASHTO CODE, UBC CODE and IS 875 CODE. Wind gusts are the extremes of the turbulent, stochastic wind field. Most of the lighting poles sway under gust and are subjected to fatigue cracking due to wind induced harmonic resonance of the lighting pole. This causes failure at the junction between base plate and the lighting pole.In order to better understand the interaction of the pole structures with wind forces, it is beneficial to have a graphical representation of the problem. The deflection at the tip of poles has been compared with different codes to gauge the performance of the poles.
\end{abstract}

Keywords: Highway Lighting poles, Dynamic loads, Wind-induced vibration and Damping

$* * *$

\section{INTRODUCTION}

This study is carried out to provide a better understanding of the effects wind has on street light structures. Wind is a dynamic and random phenomenon in both time and space. The effect of wind on a structure is three-fold. The structure must have sufficient strength to resist the wind-induced forces, the structure must have adequate stiffness to satisfy serviceability criteria, and the wind may produce a dynamic response of the structure. This third effect is of particular importance in that it may amplify the first two effects. The dynamic response of structures, in particular lighting poles to wind loading and the nature of the wind loads that produce this effect are the focus of this study. The specific wind conditions considered are low speed laminar winds, that cause vortex shedding, and gusty wind which are caused due to variations in local winds of smaller character. The variables pertaining to the structure and wind conditions include the structure's geometry, material properties as well as the wind direction, laminar wind speed and gust wind data.

\subsection{Wind Induced Vibrations}

Air flow around a structure is dependent on many variables one of which is the cross section of the structure. Pole structures are assumed here to have a circular cylinder shape. Figure 1 below shows the flow of wind around a cylinder.

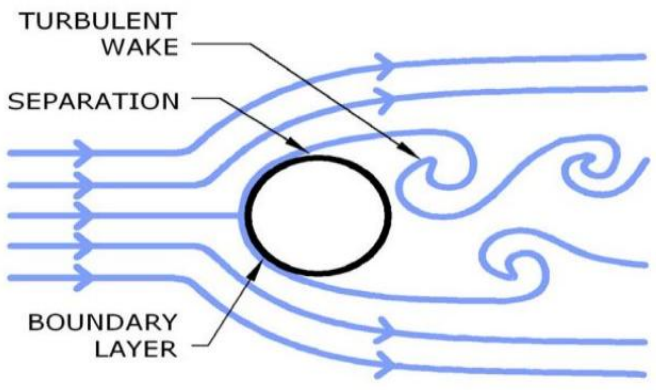

Fig -1: Flow around a cylinder

The Reynolds Number can be used to evaluate the tendency of vortex shedding to occur on a generic body (Phares, Sarkar, Wipf, \& Chang, 2007). The Reynolds number " Re " is defined as where $\mathrm{V}$ is the free stream wind speed, $\mathrm{d}$ is the projected width of the structure perpendicular to the wind flow commonly referred to as the bluff diameter and $\mathrm{V}$ is the kinematic viscosity of air. $\operatorname{Re}=(\mathrm{V} \mathrm{x} \mathrm{d}) / \mathrm{V}$

\subsection{Vortex Shedding}

Vortex shedding causes vibrations transverse to the direction of the wind. When the flow separates, low pressure vortices are formed on the leeward side of the object. When a vortex forms, it reduces the pressure on one side of the object and causes the object to move in that direction. As the flow continues, the vortices alternate sides causing the body to move back and forth transverse to the wind direction. When 
this harmonic motion approaches the natural frequency of the structure, the vortex shedding frequency can couple with the structure's natural frequency and cause significant deflections and stresses to occur. This phenomenon is referred to as "lockin". Over time these vortex-induced vibrations can fatigue a structure and eventually cause it to fail. Fatigue due to vortex shedding can be identified given knowledge of the prevailing wind direction and the orientation of cracking (Chang, Phares, Sarkar, \& Wipf, 2009).

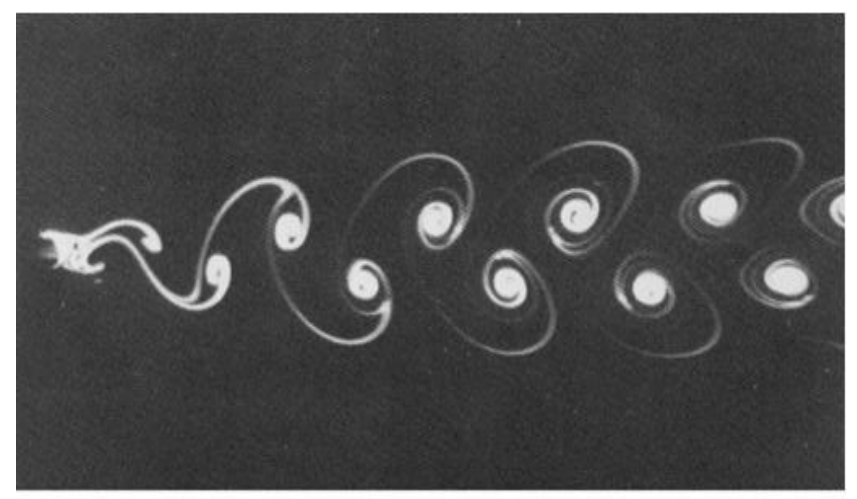

Fig -2: Vortex Street

\subsection{Vibration}

There are two common types of vibration observed in poles. First mode vibration sometimes referred to as sway, in which the maximum deflection occurs at the top of the pole, the deflection off center is not equal from side to side and it occurs at a low frequency, approximately one cycle per second, as per figure 3.This form of vibration is usually not harmful to the pole or luminaries.

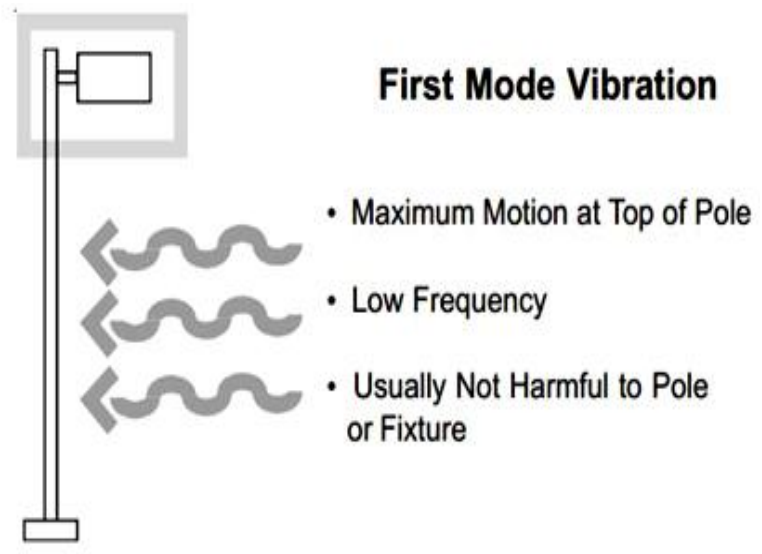

Fig- 3: First Mode of Vibration

Second mode vibration can be the most damaging form of vibration and occurs approximately at the midpoint of the pole with the deflection off center equal from side to side, figure. 4.
It is at a higher frequency; typically three to six cycles per second.

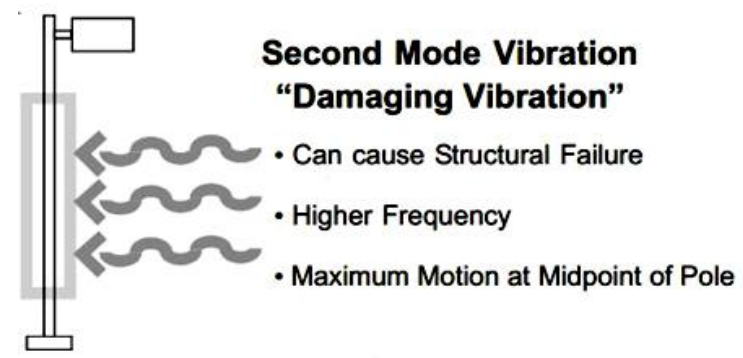

Fig- 4: Second Mode of Vibration

Second mode vibration occurs when the wind synchronizes with the natural pole vibration frequency. This is known as resonance. As the steady low level wind moves past the pole, vortices are shed alternately from either side of the structural shaft causing displacement oscillations in a direction perpendicular to that of the wind. Vortices are a swirling motion or pattern of the wind. The most serious situation arises when the vortex-shedding frequency synchronizes with the natural period of vibration in the pole, which can ultimately fatigue the pole to structural failure.

\subsection{Wind Loadings- AASHTO Loadings}

The ANSI/ASCE 7-95 is the basis for the wind load provisions of the 2001 AASHTO Supports Specifications , which includes modifications specific to the design of sign, signal, and light support structures. In addition, it used one wind speed map for the 50-year mean recurrence interval (MRI) and introduced the importance factor to obtain wind speeds for other MRIs.

\subsection{IS 875 part 31997}

The wind speeds have been worked out for 50 years return period based on the up- to-date wind data of 4 dines pressure tube ( DPT ) anemograph stations and study of other related works available on the subject since 1964. Modification factors to modify the basic wind velocity to take into account the effects of terrain ,local topography, size of structure, etc, are included.

Terrain is now classified into four categories based on characteristics of the ground surface irregularities.

\subsection{UBC 97}

The basic wind speed is the fastest-mile wind speed associated with an annual probability of 0.02 measured at a point 33 feet $(10000 \mathrm{~mm})$ above the ground for an area having exposure category C. Special Wind Region is an area where local records and terrain features indicate 50 -year fastest-mile basic wind speed .Calculation of wind loads for gust and without 
gust cases .i) Gust Effect Factor G, ii) Drag Coefficient Cd iii ) Basic Wind Speed the 3-s gust wind speed at $10 \mathrm{~m}(33 \mathrm{ft})$ above the ground associated with a 50 -yr mean recurrence interval

\section{MODELLING AND ANALYSIS}

The geometry of the pole is as follows . The mounting height of pole is $19.812 \mathrm{~m}$ with a horizontal arm length of $1.828 \mathrm{~m}$. The base of the pole is fixed and is free at the tip. For a single luminaire there is a single arm and for a double luminaire there are two arms as shown in figure 5 and figure 6. A luminaire weight of $38 \mathrm{Kg}$ at tip has been considered throughout the analysis. The FEM model has been discretized into 29 nodes and 28 elements. The steel pole has a tapering hollow circular section with a base diameter of $275 \mathrm{~mm}$ and thickness of $4.55 \mathrm{~mm}$ at node 1 to a base diameter of $166.9 \mathrm{~mm}$ and thickness of $4.55 \mathrm{~mm}$ at node 2 to a base diameter of 97 $\mathrm{mm}$ at node 3 to $69 \mathrm{~mm}$ at node 4 and of thickness $3.04 \mathrm{~mm}$.

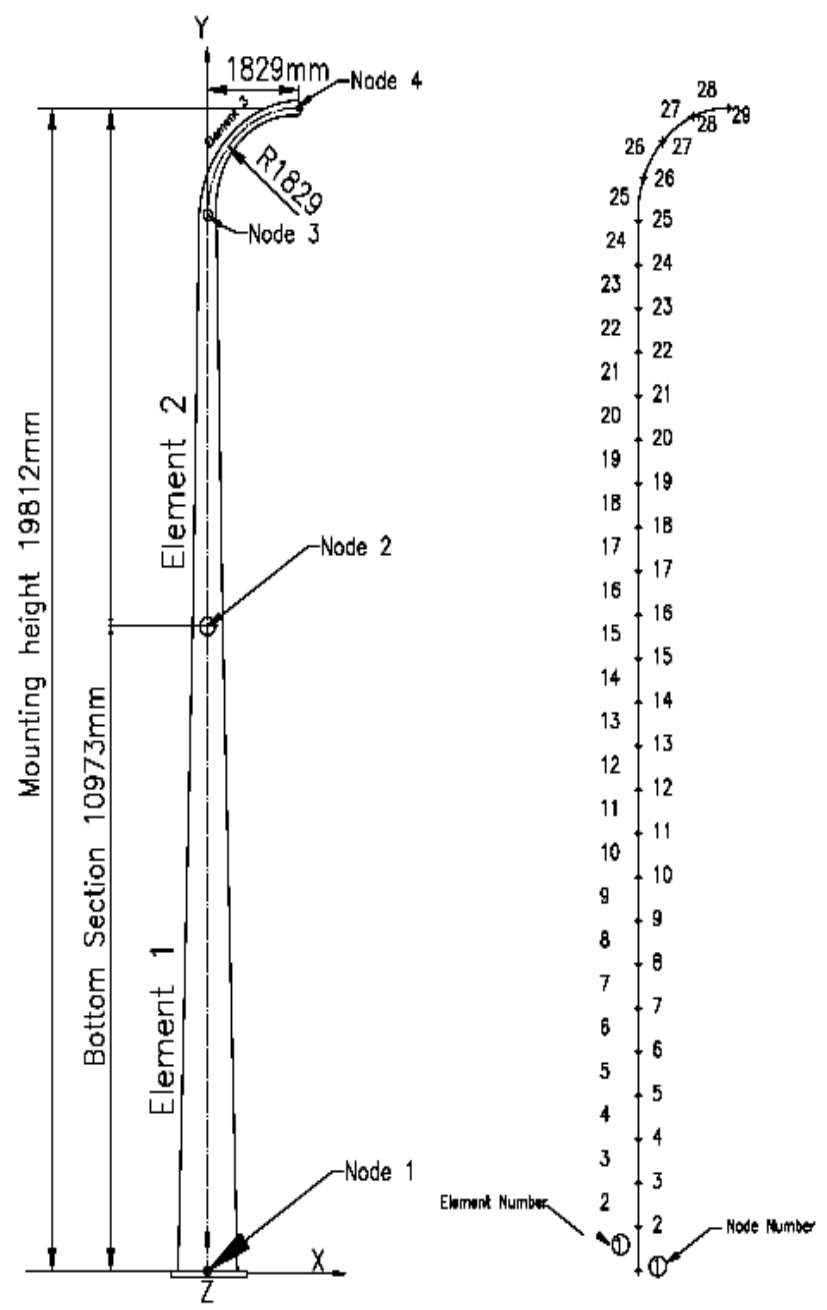

Fig -5: Single Luminaire

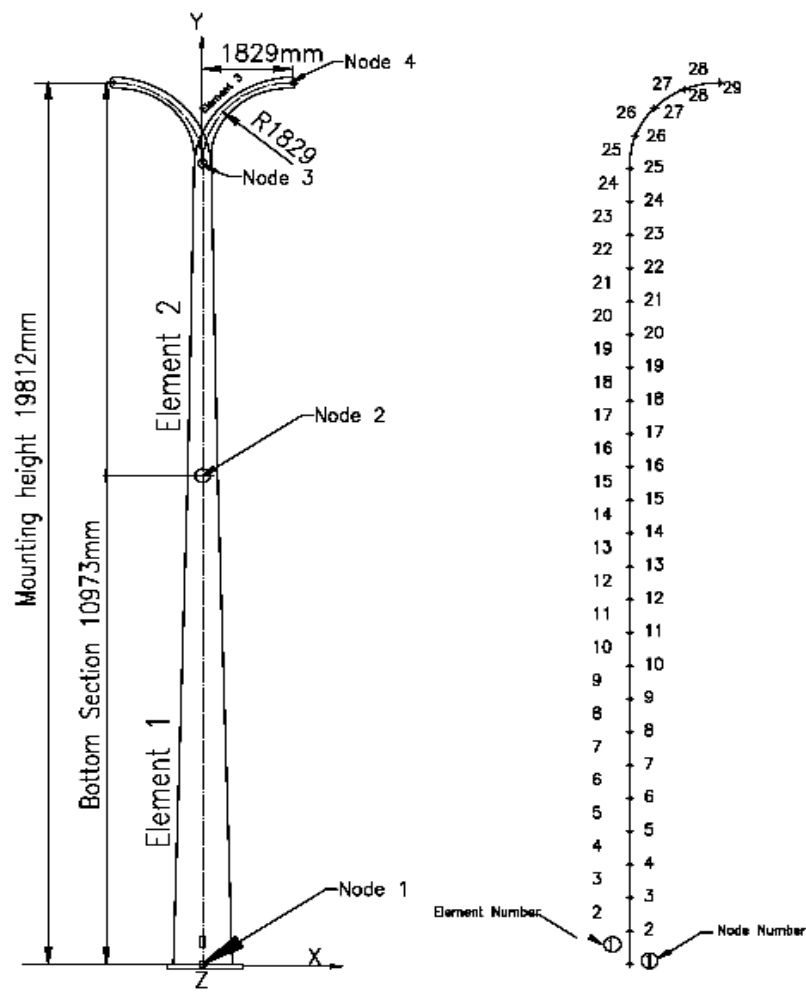

Fig -6: Double Luminaire

\subsection{Analysis}

The analysis has been done for conventional steel poles considering various types of wind loads namely

$>$ Wind with gust.

$>$ Wind without gust

A basic wind speed of $10 \mathrm{~m} / \mathrm{sec}$ was considered for the analytical study. The deflection at the tip of pole has been compared for AASHTO CODE 2001,UBC 97 and IS875 Part 31997 both for single luminaire and double luminaire. The analysis was extended for wind with gust and without gust.

\subsection{Properties of Steel Pole}

Properties based on inbuilt properties for A992Fy50 (Steel) as per SAP Software is as shown in Table 1.

Table -1: Properties of Steel

\begin{tabular}{|l|c|l|}
\hline $\begin{array}{l}\text { Young's Modulus Of } \\
\text { Elasticity E }\end{array}$ & $=$ & $2 \times 10^{8} \mathrm{kN} / \mathrm{m}^{2}$ \\
\hline Weight per unit volume $\rho$ & $=$ & $76.97 \mathrm{kN} / \mathrm{m}^{3}$ \\
\hline Poisson's Ratio $\mu$ & $=$ & 0.3 \\
\hline Shear Modulus G & $=$ & $7.69 \times 10^{7} \mathrm{kN} / \mathrm{m}^{2}$ \\
\hline
\end{tabular}




\section{RESULTS AND DISCUSSIONS}

\subsection{Codal Comparison Steel Pole}

Table -2: Single Luminaire WITH Gust

\begin{tabular}{|c|c|c|c|}
\hline $\begin{array}{c}\text { Node } \\
\text { No }\end{array}$ & $\begin{array}{c}\text { ASSHTO } \\
\text { Code 2001 }\end{array}$ & $\begin{array}{c}\text { UBC 97 } \\
\text { IS 875 Part 3 }\end{array}$ \\
\hline & $\begin{array}{c}\text { Displacement } \\
\text { in mm }\end{array}$ & $\begin{array}{c}\text { Displacement } \\
\text { in mm }\end{array}$ & $\begin{array}{c}\text { Displacement } \\
\text { in mm }\end{array}$ \\
\hline 1 & 117.5 & 143.00 & 151.6 \\
\hline 2 & 89.1 & 105.2 & 112.4 \\
\hline 3 & 7.0 & 8.5 & 9.2 \\
\hline
\end{tabular}

Legend:-SL-Single Luminaire 1- Tip Displacement 2Displacement at midpoint 3- Displacement just above base. The Chart 1 below shows that tip displacement for Single Luminaire is least for AASHTO Code and highest for IS 875 Part 3. For IS 875 Part 3 and UBC 97 Codes, the displacement values are comparable.

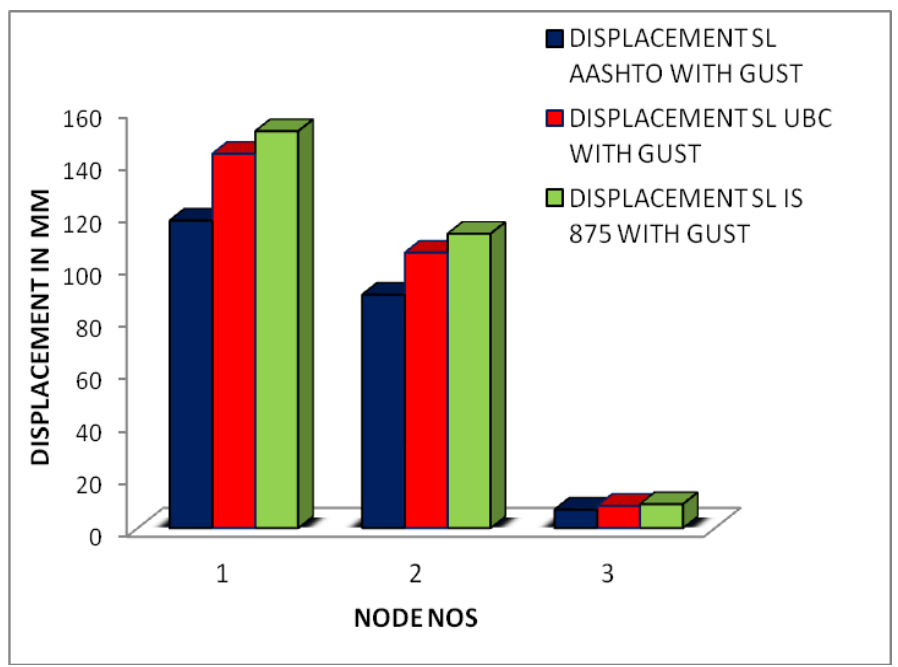

Chart -1: Codal comparison SL with gust

Table -3: Double Luminaire With Gust

\begin{tabular}{|c|c|c|c|}
\hline $\begin{array}{c}\text { Node } \\
\text { No }\end{array}$ & $\begin{array}{c}\text { ASSHTO } \\
\text { Code } 2001\end{array}$ & UBC 97 & $\begin{array}{c}\text { IS 875 } \\
\text { PART3 } 1997\end{array}$ \\
\hline & $\begin{array}{l}\text { Displacement } \\
\text { in } \mathrm{mm}\end{array}$ & $\begin{array}{l}\text { Displacement } \\
\text { in } \mathrm{mm}\end{array}$ & $\begin{array}{l}\text { Displacement } \\
\text { in } \mathrm{mm}\end{array}$ \\
\hline 1 & 71.9 & 108.4 & 119.7 \\
\hline 2 & 53.0 & 83.3 & 92.7 \\
\hline 3 & 5.4 & 8.2 & 9.0 \\
\hline
\end{tabular}

Legend:-DL-Double Luminaire 1- Tip Displacement 2Displacement at midpoint 3- Displacement just above base.

The Chart 2 below shows that tip displacement for Double Luminaire is least for AASHTO Code and highest for IS 875
Part 3. For IS 875 Part 3 and UBC 97 Codes, the displacement values are comparable.

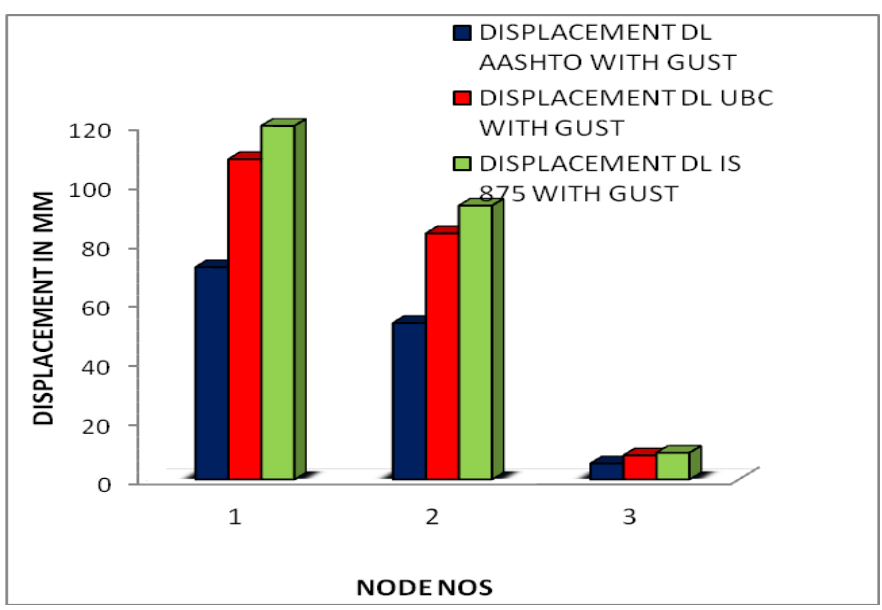

Chart -2: Codal comparison DL with gust

Table -4: Single Luminaire WITHOUT Gust

\begin{tabular}{|c|c|c|c|}
\hline $\begin{array}{c}\text { Node } \\
\text { No }\end{array}$ & $\begin{array}{c}\text { ASSHTO } \\
\text { Code 2001 }\end{array}$ & IS 875 Part3 & UBC 97 \\
\hline & $\begin{array}{c}\text { Displacement } \\
\text { in mm }\end{array}$ & $\begin{array}{c}\text { Displacement } \\
\text { in mm }\end{array}$ & $\begin{array}{c}\text { Displacement } \\
\text { in mm }\end{array}$ \\
\hline 1 & 105.6 & 110.1 & 121.6 \\
\hline 2 & 73.7 & 77.4 & 87.2 \\
\hline 3 & 5.2 & 5.5 & 6.7 \\
\hline
\end{tabular}

Legend:-SL-Single Luminaire 1- Tip Displacement 2Displacement at midpoint 3- Displacement just above base.

The Chart 3 below shows that tip displacement for Single Luminaire is least for AASHTO Code and highest for UBC 97 Code. For IS 875 Part 3 and AASHTO Code, the displacement values are comparable.

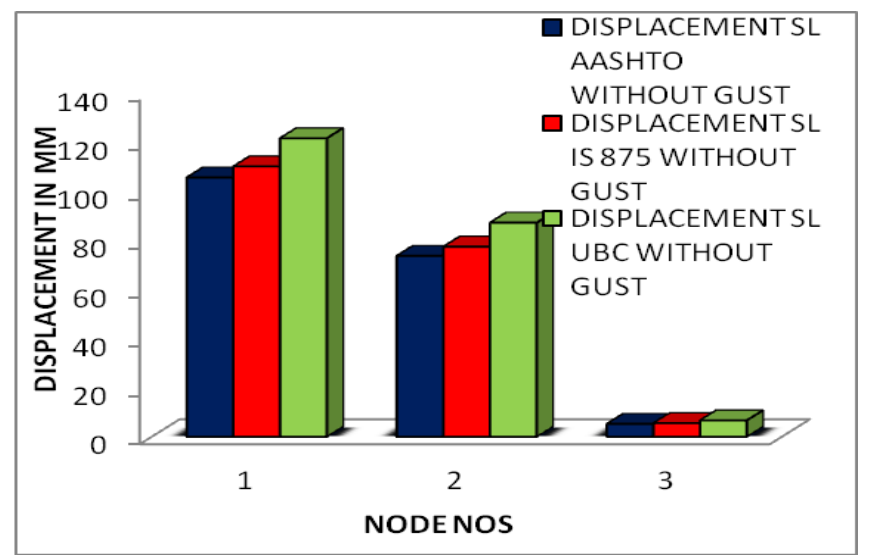

Chart -3: Codal comparison SL without gust 
Table -5: Double Luminaire without Gust

\begin{tabular}{|c|c|c|c|}
\hline $\begin{array}{c}\text { Node } \\
\text { No }\end{array}$ & $\begin{array}{c}\text { ASSHTO } \\
\text { Code 2001 }\end{array}$ & $\begin{array}{c}\text { IS 875 Part3 } \\
\mathbf{1 9 9 7}\end{array}$ & \begin{tabular}{c} 
UBC 97 \\
\hline
\end{tabular} \\
\hline $\begin{array}{c}\text { Displacement } \\
\text { in mm }\end{array}$ & $\begin{array}{c}\text { Displacement } \\
\text { in mm }\end{array}$ & $\begin{array}{c}\text { Displacement } \\
\text { in mm }\end{array}$ \\
\hline 1 & 59.6 & 66.2 & 80.1 \\
\hline 2 & 42.6 & 48.0 & 59.8 \\
\hline 3 & 4.2 & 4.7 & 5.9 \\
\hline
\end{tabular}

Legend:-SL-Single Luminaire 1- Tip Displacement 2Displacement at midpoint 3- Displacement just above base. The Chart 4 below shows that tip displacement for Double Luminaire is least for AASHTO Code and highest for UBC 97 Code. For IS 875 Part 3 and AASHTO Code, the displacement values are comparable.

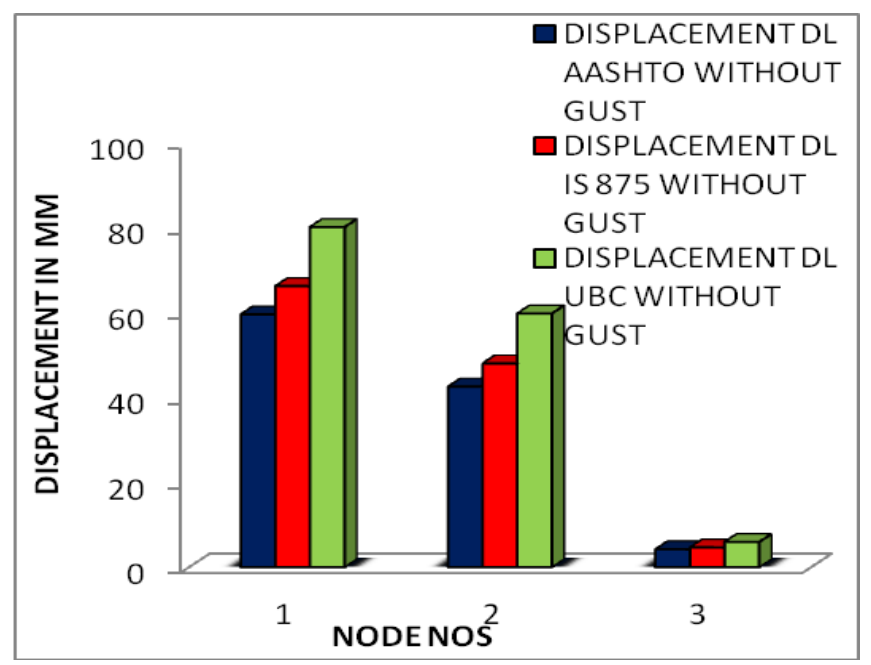

Chart -4: Codal comparison DL without gust

\subsection{Aashto code 2001}

Table -6: Single and Double Luminaire With Gust

\begin{tabular}{|c|c|c|}
\hline Node No & $\begin{array}{c}\text { Single Luminaire } \\
\text { Displacement in } \\
\text { mm }\end{array}$ & $\begin{array}{c}\text { Double Luminaire } \\
\text { Displacement in } \\
\text { mm }\end{array}$ \\
\hline 1 & 117.5 & 71.9 \\
\hline 2 & 89.1 & 53.0 \\
\hline 3 & 7.0 & 5.4 \\
\hline
\end{tabular}

Legend:-SL-Single Luminaire DL-Double Luminaire Legend:-SL-Single Luminaire 1- Tip Displacement 2Displacement at midpoint 3- Displacement just above base. The Chart 5 below shows the displacement at tip for Single and Double luminaire for AASHTO Code are $117.5 \mathrm{~mm}$ and
$71.9 \mathrm{~mm}$ respectively. The variation of displacement for single and double luminaire is $39 \%$.

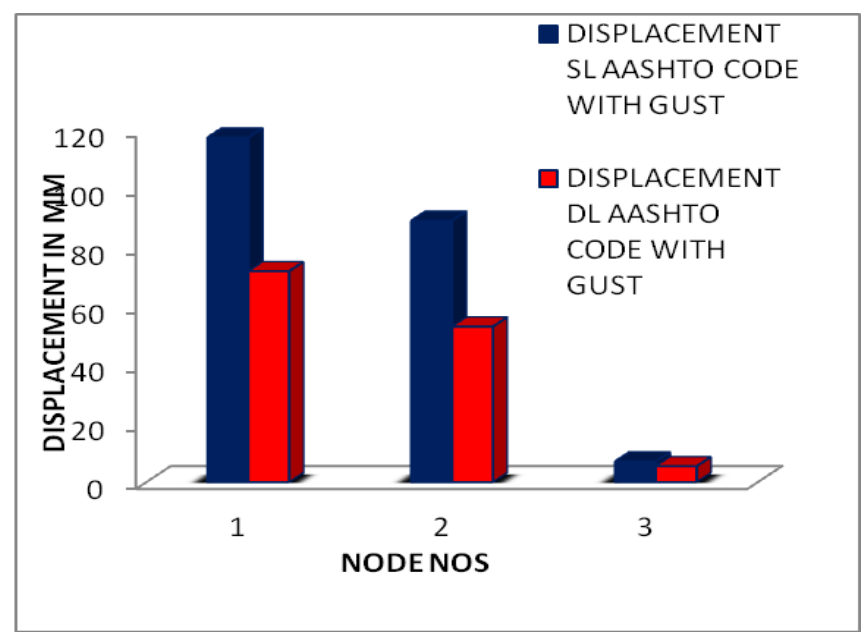

Chart -5: AASHTO Code SL and DL with gust

Table -7: Single and Double Luminaire Without Gust

\begin{tabular}{|c|c|c|}
\hline $\begin{array}{c}\text { Node } \\
\text { No }\end{array}$ & Single Luminaire & Double Luminaire \\
\hline & Displacement in mm & $\begin{array}{c}\text { Displacement in } \\
\text { mm }\end{array}$ \\
\hline 1 & 105.6 & 59.6 \\
\hline 2 & 73.7 & 42.6 \\
\hline 3 & 5.2 & 4.2 \\
\hline
\end{tabular}

Legend:-SL-Single Luminaire 1- Tip Displacement 2Displacement at midpoint 3- Displacement just above base. The Chart 6 below shows the displacement at tip for Single and Double luminaire for AASHTO Code as $105.6 \mathrm{~mm}$ and $59.6 \mathrm{~mm}$ respectively. The variation of displacement for single and double luminaire for "without gust" case is $44 \%$.

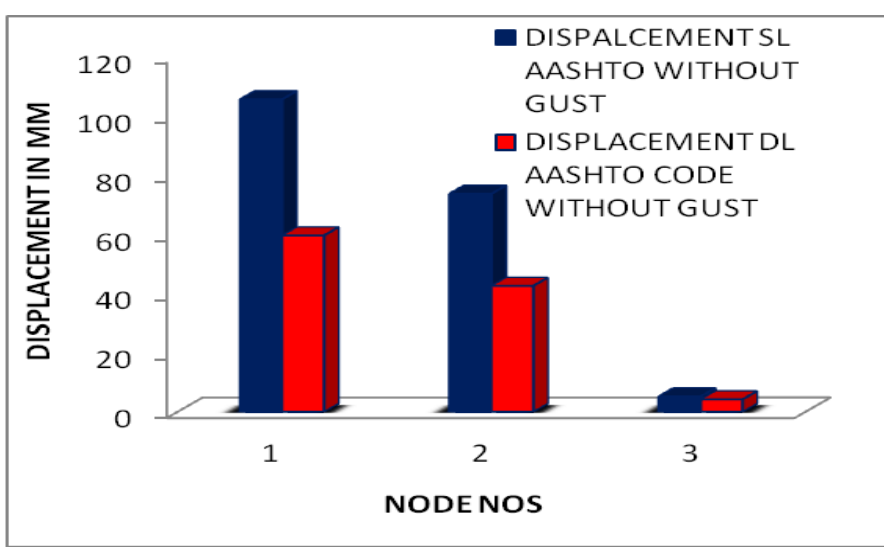

Chart -6: AASHTO Code SL and DL without gust 


\subsection{IS 875 Part 31997}

Table -8: Single and Double Luminaire With Gust

\begin{tabular}{|c|c|c|}
\hline Node No & Single Luminaire & Double Luminaire \\
\hline & $\begin{array}{c}\begin{array}{c}\text { Displacement in } \\
\text { mm }\end{array} \\
\end{array}$ & $\begin{array}{c}\text { Displacement in } \\
\mathrm{mm}\end{array}$ \\
\hline 1 & 151.6 & 71.9 \\
\hline 2 & 112.4 & 53.0 \\
\hline 3 & 9.2 & 5.4 \\
\hline
\end{tabular}

The Chart 7 below shows the displacement at tip for Single and Double luminaire for IS 875 Part 31997 as $151.6 \mathrm{~mm}$ and $71.9 \mathrm{~mm}$ respectively. The variation of displacement for single and double luminaire for "with gust" case is $53 \%$.

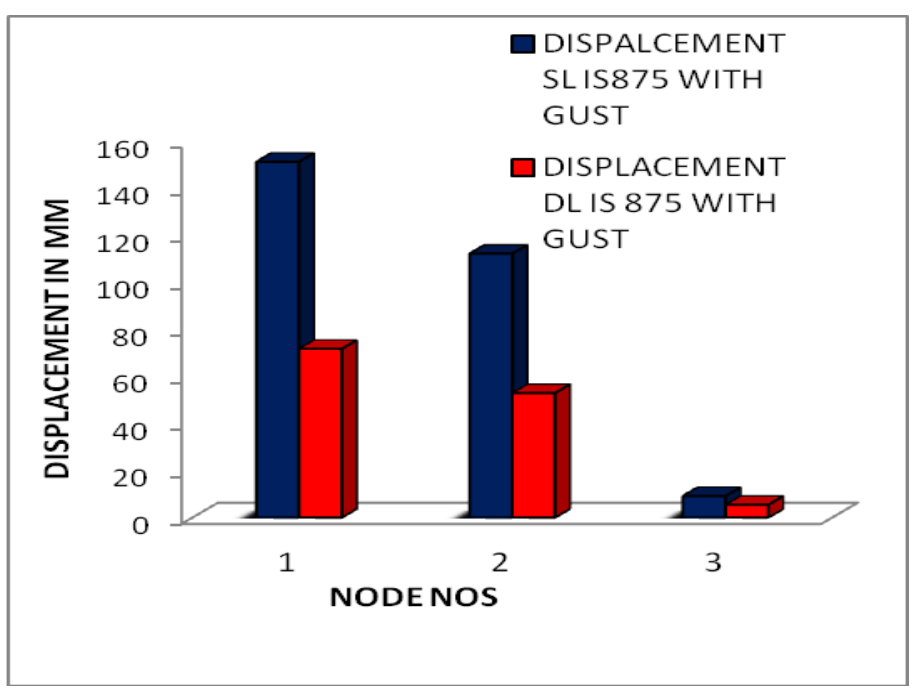

Chart -7: SL and DL with gust

Table -9: Single and Double Luminaire Without Gust

\begin{tabular}{|c|c|c|}
\hline Node No & Single Luminaire & $\begin{array}{c}\text { Double } \\
\text { Luminaire }\end{array}$ \\
\hline & $\begin{array}{c}\text { Displacement in } \\
\text { mm }\end{array}$ & $\begin{array}{c}\text { Displacement in } \\
\text { mm }\end{array}$ \\
\hline 1 & 110.1 & 66.2 \\
\hline 2 & 77.4 & 48.0 \\
\hline 3 & 5.5 & 4.7 \\
\hline
\end{tabular}

The Chart 8 below shows the displacement at tip for single and double luminaire for IS 875 Part 31997 as $110.1 \mathrm{~mm}$ and $66.2 \mathrm{~mm}$ respectively. The variation of displacement for single and double luminaire for "without gust" case is $40 \%$.

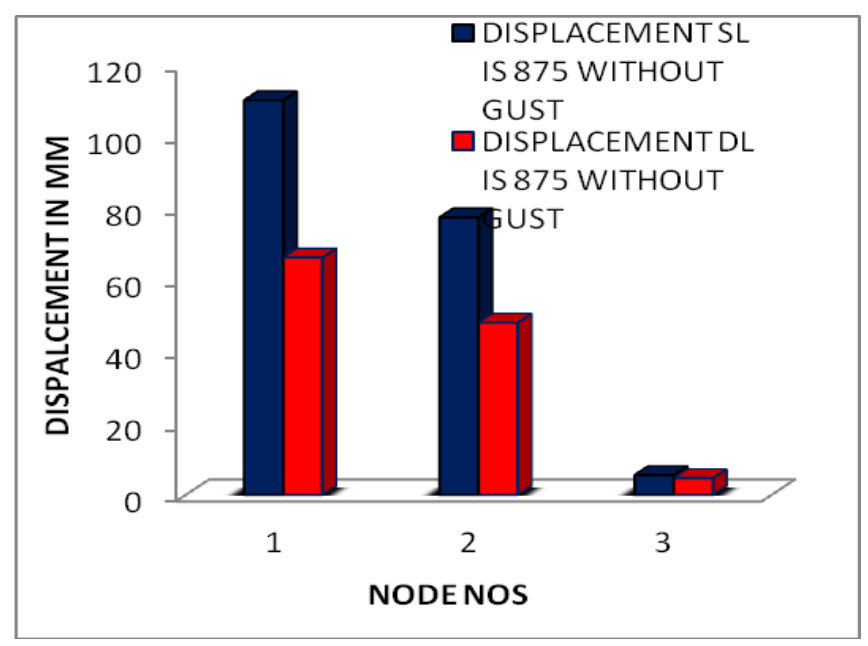

Chart -8: SL and DL without gust

\subsection{UBC 97 Code}

Table -10: Single and Double Luminaire With Gust

\begin{tabular}{|c|c|c|}
\hline Node No & Single Luminaire & \begin{tabular}{c} 
Double Luminaire \\
\hline
\end{tabular} \\
\hline 1 & 143.0 & $\begin{array}{c}\text { Displacement in } \\
\text { mm }\end{array}$ \\
\hline 2 & 105.2 & 108.4 \\
\hline 3 & 8.5 & 83.3 \\
\hline
\end{tabular}

The Chart 9 below shows the displacement at tip for Single and Double luminaire for UBC 97 Code as $143.0 \mathrm{~mm}$ and $108.4 \mathrm{~mm}$ respectively. The variation of displacement for single and double luminaire for "with gust" case is $24 \%$.

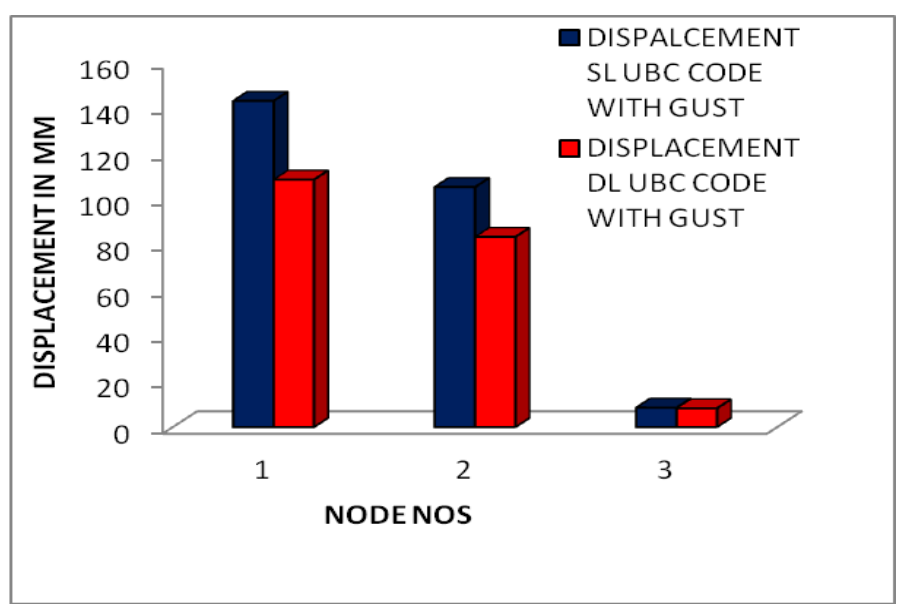

Chart -9: SL and DL with gust 
Table -11 Single and Double Luminaire without Gust

\begin{tabular}{|c|c|c|}
\hline Node No & Single Luminaire & Double Luminaire \\
\hline & Displacement in mm & $\begin{array}{c}\text { Displacement in } \\
\text { mm }\end{array}$ \\
\hline 1 & 121.6 & 80.1 \\
\hline 2 & 87.2 & 59.8 \\
\hline 3 & 6.7 & 5.9 \\
\hline
\end{tabular}

The Chart 10 below shows the displacement at tip for Single and Double luminaire for UBC 97 Code as $121.6 \mathrm{~mm}$ and 80.1 $\mathrm{mm}$ respectively. The variation of displacement for single and double luminaire for "without gust" case is $34 \%$

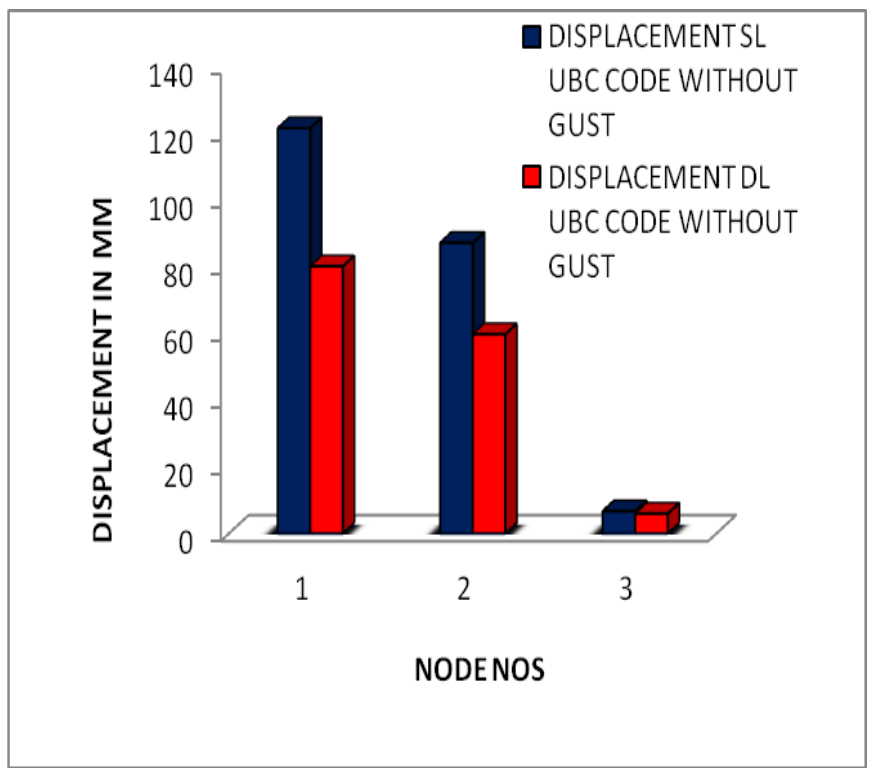

Chart -10: SL and DL without gust

\section{CONCLUSIONS}

Based on the analytical studies the following conclusions may be drawn.

1. The tip displacement for poles, single and double luminaire for wind loads with gust are highest for IS 875 Code and the least for AASHTO Code.

2. The tip displacement for poles, single and double luminaire for wind loads without gust are highest for UBC 97 Code and the least for AASHTO Code.

3. Single luminaire poles are more susceptible to any type of wind excitations compared to Double luminaire poles.

4. The UBC 97 Code has shown a least variation in the performance of single and double luminaire poles for both wind with gust and without gust cases.

\section{REFERENCES}

[1]. Wayne Flather, (1997), "Wind Induced Vibrations of Pole Structures', Project done in University of Manitoba, US.

[2]. Kenneth F. Dunker et al., (2002)," Vibration Monitoring of Luminaries on the Burlington Cable-Stayed Bridge", Prepared for The Iowa Department of Transportation, The Bridge Engineering Center at the Center for Transportation Research and Education- Iowa State University.

[3]. Luca Caracoglia, Antonio Velazquez (2007) Department of Civil and Environmental Engineering, Northeastern University, Boston, MA 02115, USA "Experimental comparison of the dynamic performance for steel, aluminum and glass-fiber-reinforced-polymer light poles"

[4]. Caracoglia L, Jones NP. (200 mitigation for highway light poles".7) "Numerical and experimental study of vibration ". Engineering Structures;29(5):821-31

\section{BIOGRAPHIES}

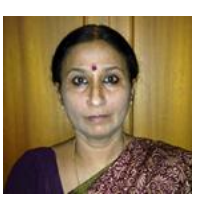

Mrs. Suma Devi graduated from NSS College of Engineering; Palakkad affiliated to University of Calicut, and later did her post graduation from UVCE, Bangalore University, in Earthquake Engineering. She is currently working as Assistant Professor in Sri Venkateshwara College of Engineering, Bangalore 562157.

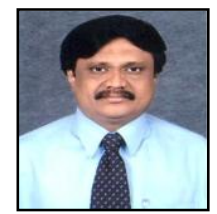

Dr. L.Govindaraju is currently Associate Professor, in the Department of Civil Engineering, UVCE, Bangalore University, Bangalore 